\title{
A novel biochemical method to identify target genes of individual microRNAs: Identification of a new Caenorhabditis elegans let-7 target
}

\author{
YOSHIKI ANDACHI ${ }^{1,2}$ \\ ${ }^{1}$ Genome Biology Laboratory, Center for Genetic Resource Information, National Institute of Genetics, Research Organization of Information \\ and Systems, Mishima 411-8540, Japan \\ ${ }^{2}$ Department of Genetics, School of Life Science, The Graduate University for Advanced Studies (SOKENDAI), Mishima 411-8540, Japan
}

\begin{abstract}
MicroRNAs (miRNAs) are roughly 22-nucleotide regulatory RNAs that play important roles in many developmental and physiological processes. Animal miRNAs down-regulate target genes by forming imperfect base pairs with $3^{\prime}$ untranslated regions ( $3^{\prime}$ UTRs) of their mRNAs. Thousands of miRNAs have been discovered in several organisms. However, the target genes of almost all of these miRNAs remain to be identified. Here, we describe a method for isolating cDNA clones of target mRNAs that form base pairs in vivo with an endogenous miRNA of interest, in which the cDNAs are synthesized from the mRNAs using the miRNA as a reverse-transcription primer. The application of this method to Caenorhabditis elegans miRNA lin-4 under test conditions yielded many clones of the known target gene lin-14 that correspond to partial sequences $5^{\prime}$ to lin-4 binding sites in the 3' UTR. The method was also applied to $C$. elegans miRNA let-7 and a new target gene responsible for the lethal phenotype in let-7 mutants was identified. These results demonstrate that the method is a useful way to identify targets on the basis of base pairing with individual miRNAs.
\end{abstract}

Keywords: miRNA; target gene; base pairing; C. elegans; lin-4; let-7

\section{INTRODUCTION}

MicroRNAs (miRNAs) constitute a large class of genomically encoded, noncoding RNAs present across eukaryotic phylogeny (Bartel 2004). These RNAs are transcribed as longer precursor RNAs, which undergo multiple processing steps to produce $\sim 22$-nucleotide (nt) mature miRNAs. Animal miRNAs down-regulate target genes by forming imperfect base pairs with $3^{\prime}$ untranslated regions (3' UTRs) of their mRNAs. A small number of miRNAs have been shown to be implicated in the development of early embryos, neurons, muscles, and lymphocytes, and to be causal to genetic disorders and cancers along with target genes involved in these biological phenomena (Kloosterman and Plasterk 2006; Stefani and Slack 2008). Beside these miRNAs, thousands of miRNAs have been discovered in several

Reprint requests to: Yoshiki Andachi, Genome Biology Laboratory Center for Genetic Resource Information, National Institute of Genetics, Research Organization of Information and Systems, Mishima 411-8540, Japan; e-mail: yandachi@lab.nig.ac.jp; fax: 81-55-981-6855.

Article published online ahead of print. Article and publication date are at http://www.rnajournal.org/cgi/doi/10.1261/rna.1139508. organisms (Griffiths-Jones et al. 2008). The identification of target genes is a major challenge in elucidating the functions of miRNAs.

A common feature of known miRNA-target combinations is almost perfect base pairing between the second and eighth nucleotides from the $5^{\prime}$ end of the miRNA, the seed sequence, and complementary nucleotides in the 3' UTRs of the mRNAs (Bartel 2004). Several computational algorithms have been developed to predict target genes of each miRNA based on sequence alignments to detect complementary sequences in the $3^{\prime}$ UTR with the seed sequence (Lewis et al. 2003; Krek et al. 2005; Rajewsky 2006; Griffiths-Jones et al. 2008). The predicted targets need to be experimentally validated, especially for direct interactions between the miRNA and the target mRNAs, because in silico analyses do not consider whether the miRNA and the mRNAs are expressed in the same cells. Furthermore, perfect seed pairing does not necessarily assure down-regulation of the predicted genes (Didiano and Hobert 2006) and partial seed pairing can be functional, especially when the $3^{\prime}$ half of the miRNA forms a continuum of base pairs with the mRNAs (Brennecke et al. 2005; Didiano and Hobert 2006, 2008). The flanking regions of complementary sequences in the $3^{\prime}$ UTRs 
also influence the availability of the sequences (Vella et al. 2004; Didiano and Hobert 2006, 2008).

A biochemical method used to identify target genes of individual miRNAs is the detection of a miRNA-induced reduction of target mRNAs by microarray analysis; it has been shown that miRNAs not only repress the translation of target mRNAs, but also promote their degradation (Bagga et al. 2005). The detected targets need to demonstrate direct interaction with the miRNA to show that the reductions of target mRNAs are directly caused by the miRNA. Moreover, the microarray approach needs two samples, between which the expression levels of the miRNA are different; at least one of them is usually an engineered or genetically altered sample, such as cultured cells transfected with synthetic precursors of the miRNA (Lim et al. 2005) or zebrafish embryos with a mutation in the Dicer gene (Giraldez et al. 2006). This requirement greatly restricts the types of organisms to which the microarray method is applicable.

The interaction of mRNAs with miRNAs is deduced from binding of the mRNAs to the RNA-induced silencing complex (RISC), where a miRNA is an RNA component (Bartel 2004). Analyses of samples collected from cytoplasmic extract by immunoprecipitation against RISC protein components specific for miRNA reveal mRNAs included in the RISC (Easow et al. 2007; Karginov et al. 2007; Zhang et al. 2007). The method essentially gives no information on miRNA-target combinations. Another method for detecting miRNA-mRNA complexes was proposed by Vatolin et al. (2006), in which cytoplasmic extract was reacted with reverse transcriptases to indicate that an endogenous miRNA can be a primer for cDNA synthesis on a target mRNA template. The cDNA fragment was ligated to an adapter oligonucleotide at the $5^{\prime}$ terminus and amplified by polymerase chain reaction (PCR) with a primer from the adapter and a genespecific primer corresponding to the target mRNA. The $5^{\prime}-$ terminal analyses of cloned PCR fragments show signature sequences that help to identify the miRNA. These researchers demonstrated that the method is useful for detecting miRNAs that regulate specified genes. However, equally or even more eagerly desired is a method to identify targets regulated by the miRNA whose function interests the researcher.

We have developed a novel method to identify target genes of individual miRNAs by isolation of cDNA clones of mRNAs with which a miRNA of interest forms base pairs in vivo. Because the first two miRNAs, lin-4 and let-7, were discovered in C. elegans (Lee et al. 1993; Wightman et al. 1993; Reinhart et al. 2000), this animal is one of the most intensively studied organisms in the field of miRNA research. More than 150 miRNAs have been discovered (LagosQuintana et al. 2001; Lau et al. 2001; Lee and Ambros 2001; Ambros et al. 2003; Grad et al. 2003; Jackson et al. 2003; Lim et al. 2003; Ohler et al. 2004; Ruby et al. 2006, 2007; Gu et al. 2007; Zhang et al. 2007; Friedlander et al. 2008; Griffiths-Jones et al. 2008) and knockout phenotypes of most of the miRNAs have been reported (Miska et al. 2007).
The method was applied to the two C. elegans miRNAs and resulted in the isolation of many cDNA clones of the lin-4 target gene lin-14 and the identification of a new let-7 target gene, demonstrating the usefulness of the method.

\section{RESULTS}

\section{Cloning of cDNAs synthesized by reverse transcription of target mRNAs using an endogenous miRNA of interest as a primer}

Because a miRNA works in the RISC, it is likely that protein components of the RISC prevent a reverse transcriptase from contacting the miRNA on target mRNAs, resulting in inefficient priming from the miRNA. Other RNA-binding proteins on the mRNAs may also block the elongation of cDNA strands. However, treatment with denaturing agents or the use of high-temperature reactions to strip proteins from the mRNAs can easily disrupt base pairing between the miRNA and mRNAs. To meet both the requirements of removing proteins and maintaining base pairing, we subjected cytoplasmic extract to short-term treatment with a strong detergent at low temperature to destabilize proteins. The treated extract was diluted in reverse-transcription reaction buffer until reverse transcriptases were no longer susceptible to the detergent, and incubated first at low temperature for the synthesis of short cDNAs to strengthen the binding of the miRNA to target mRNAs, then at higher temperature for the synthesis of long cDNAs requiring the disruption of mRNA secondary structure. As shown in Figure 1a, double-stranded cDNA fragments were amplified by PCR with a biotin-tagged PCR primer corresponding to a miRNA to purify PCR fragments including the miRNA sequence; the PCR fragments were then cloned and sequenced.

False-positive clones are possible when the miRNA PCR primer anneals to partially complementary sequences on cDNAs from nontarget mRNAs, producing PCR fragments. To distinguish such false-positive clones, we did not use all of the miRNA nucleotides for the miRNA PCR primer, but rather excluded a few nucleotides from the $3^{\prime}$ end (Fig. 1b). The probability that the $3^{\prime}$-end sequence would be located adjacent to the primer sequence in false-positive clones was very low, whereas clones derived from cDNAs synthesized by reverse transcription from true target mRNAs should contain the miRNA sequence, including the $3^{\prime}$ end. Those clones with the expected sequence structure were collected from all sequenced clones.

\section{Isolation of lin-14 3' UTR clones by application of the method to lin-4}

The miRNA lin-4 and its target gene lin-14 were discovered first among all miRNA-target combinations (Lee et al. 
1993; Wightman et al. 1993) and the lin-14 3' UTR contains seven lin-4 binding sites ( $\mathrm{Ha}$ et al. 1996). The ratio of lin-14 3' UTR clones among all sequenced clones isolated to identify lin-4 targets was used as a quantitative indicator. The method was examined under two conditions that were advantageous, but not specific, for isolating lin-14 3' UTR clones. First, the cell extract was prepared from a C. elegans population synchronized at the second larval $\left(\mathrm{L}_{2}\right)$ stage when lin-4 miRNAs accumulate (Feinbaum and Ambros 1999); second, the HaeII restriction endonuclease used (see Fig. 1a) has a recognition sequence located just 5' of the lin-4 binding sites. To evaluate the method, a cDNA library was prepared under each of a number of test conditions, and 96 clones randomly picked from the library were analyzed. For example, potential false-positive clones could be derived from binding to nontarget mRNAs by free lin-4 miRNAs that were released from free RISCs or detached from target mRNAs before or in the course of the reverse-transcription reaction. The production of such false-positive clones should result in a marked reduction in the ratio of $l i n-14$ clones. For one test condition, we added 2 '-O-methyloligonucleotide complementary to the lin-4 miRNA in the cell extract buffer to sequester free lin-4 miRNAs through base pairing with the oligo. The addition of the oligo resulted in no significant difference in the ratio of lin-14 clones compared with test conditions without the oligo (data not shown), suggesting that free lin-4 miRNAs, if any, are inadequate primers for reverse transcription of nontarget mRNAs. Subsequent to this experiment, the addition of antisense oligos was omitted from the method.

Among the top 10 results from 34 experiments with different test conditions, the average frequency of lin-14 3' UTR clones eventually reached $73.8 \%$, indicating that the method is highly efficient for isolating target clones. In total, 1451 clones that consisted of partial sequences of the lin-14 3' UTR were isolated (Fig. 2). A sequence alignment of the clones with the $3^{\prime}$ UTR showed that the $3^{\prime}$ terminus of each clone was located in the $5^{\prime}$ vicinity of any one of the lin-4 binding sites in many of the clones, and there were no clones in which the cloned sequences extended beyond all of the lin-4 binding sites, indicating that the method is highly specific.

\section{The identification of a new let-7 target}

We further evaluated the method by attempting to identify new targets of another C. elegans miRNA, let-7, which has pleiotropic functions in development (Reinhart et al. 2000). The let-7 mutants exhibit retarded heterochronic defects in seam cells at the $\mathrm{L}_{4}$-to-adult molt and undergo an extra molt at the adult stage (Reinhart et al. 2000; Hayes et al. 2006). All worms homozygous for null allele let-7(mn112) die at the young-adult stage due to bursting through the vulva, resulting in the generation of few fertilized eggs (Reinhart et al. 2000; Slack et al. 2000). let-7 is expressed at the $\mathrm{L}_{3}$ and later stages (Reinhart et al. 2000; Lim et al. 2003). Although several genes, including lin-41, hbl-1, let60 , and daf-12 have been identified to be let-7 targets, mutations in these genes only partially suppress the vulval bursting phenotype (Slack et al. 2000; Abrahante et al. 2003; Lin et al. 2003; Grosshans et al. 2005; Johnson et al. 2005), suggesting that other genes involved in the lethal phenotype remain to be identified. Therefore, we sought let-7 targets responsible for the bursting phenotype in worms at each of the $\mathrm{L}_{3}, \mathrm{~L}_{4}$, and young-adult stages.
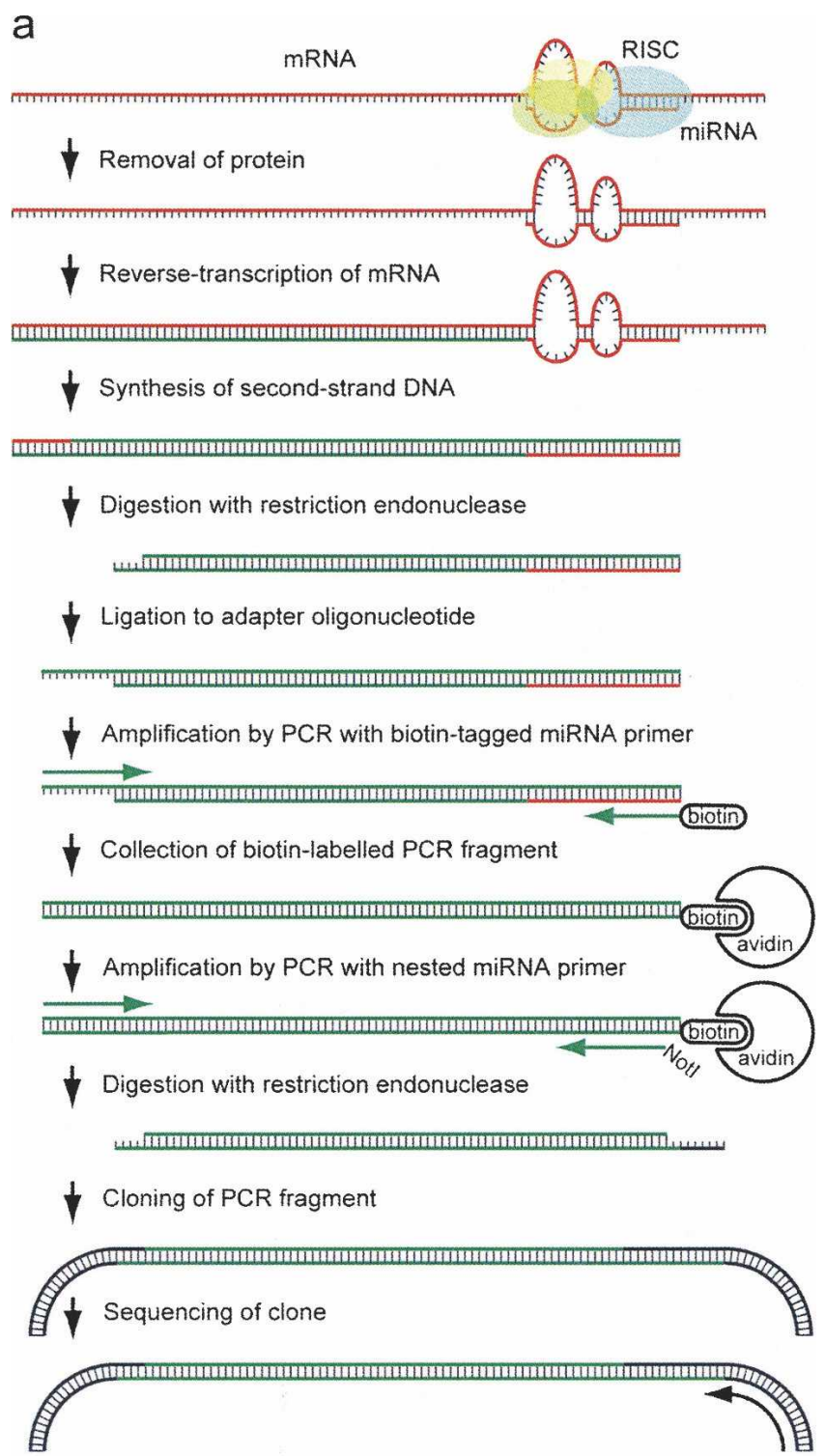

b

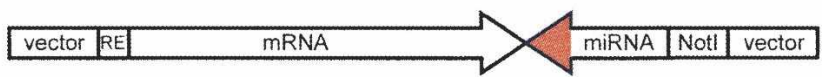

FIGURE 1. (Legend on next page) 
Sequence analyses of 672 isolated clones revealed that 159 clones contained the let-7 miRNA sequence, and the collected clones corresponded to 73 genes (Supplemental Fig. 1). An alignment of the cloned sequences with the genes also revealed that the $3^{\prime}$ termini of the sequences were located either in the $3^{\prime}$ UTRs or in the coding regions close to the 3' UTRs for 40 of the genes, which were chosen as primary candidates (Table 1). To see if decreased activity of the candidate genes suppressed the vulval bursting phenotype as with known let-7 targets, let-7(mn112) worms were subjected to RNA interference (RNAi) for each of the 40 genes. Partial suppression of lethality was exhibited by the generation of many fertilized eggs for five of the genes (Table 1). To know what defects were induced by expression of each of the five genes without regulation mediated by the 3 ' UTR, genomic DNA containing the coding region of each gene along with the promoter was cloned to produce a construct containing the $3^{\prime}$ UTR of the unc-54 myosin gene. For one of the genes, K10C3.4, a substantial number of transgenic worms containing its construct experienced bursting through the vulva (Table 2).

K10C3.4 has two promoters deduced from the structures of K10C3.4 cDNA clones (provided by the extensive $C$. elegans cDNA project, Y. Kohara, http://nematode.lab.nig. ac.jp/), both of which have the trans-splicing leader SL1 at the $5^{\prime}$ terminus (Fig. 3a). The expression of a GFP reporter containing $8.6 \mathrm{~kb}$ of genomic DNA upstream of the K10C3.4 coding region began in embryos and was observed at the $\mathrm{L}_{4}$ stage in vulval cells, seam cells, distal-tip cells, pharyngeal cells, rectal epithelial cells, and several neurons (Fig. 3b). GFP reporters containing the let-7 promoter are expressed in vulval cells and seam cells at late larval stages and in distal-tip cells at the adult stage (Johnson et al. 2003;

FIGURE 1. Schematic of the method for isolating cDNA clones of mRNAs with which an endogenous miRNA forms base pairs. (a) Step-by-step description of the procedure. RNA and DNA strands are depicted in red and green, respectively. Worms were homogenized to prepare cytoplasmic extract. The extract was mixed with a detergent to destabilize proteins and incubated in a reverse-transcription reaction buffer to synthesize a first-strand cDNA using the miRNA as a primer. Polynucleotides collected from the buffer were incubated in a second-strand synthesis reaction buffer to synthesize DNA complementary to both the first-strand cDNA and the miRNA. After digestion of the double-stranded cDNA with a restriction endonuclease, the cDNA fragments were ligated to an adaptor oligonucleotide and then amplified by PCR with an adapter PCR primer and a biotintagged miRNA PCR primer corresponding to a partial sequence of the miRNA. Biotin-labeled PCR fragments were collected by binding to avidin beads and amplified by PCR with an adapter PCR primer and a nested miRNA PCR primer containing the NotI recognition sequence. Amplification fragments were digested with the same restriction endonuclease and NotI, and cloned into a vector. The sequences of inserts in randomly selected clones were determined with a vector primer. (b) Structure of a clone derived from a cDNA synthesized by reverse-transcription using a miRNA as a primer. The $5^{\prime}$-to- $3^{\prime}$ directions of the mRNA and the miRNA sequences are indicated by arrows. The $3^{\prime}$-end of the miRNA excluded from the miRNA PCR primer is drawn in red.
Esquela-Kerscher et al. 2005). Of the tissues where K10C3.4 is expressed, only in the pharynx was expression directed by the upstream promoter (Fig. 3c), whereas expression in most tissues was directed by the downstream promoter (Fig. 3d). K10C3.4 has orthologs in phylogenetically related nematodes C. briggsae and C. remanei (Rogers et al. 2008), and shows homology with highly conserved vertebrate genes sharing the same name, Transmembrane protein 98 (Fig. 3g; Flicek et al. 2008). The functions of these genes are unknown, but they contain conserved transmembrane domains at the N-termini. Indeed, a C-terminal GFP fusion protein of K10C3.4 was localized to cell membrane (Fig. $3 e, f)$. A let-7 binding site, with a sequence complementary to the let-7 seed, is located in the $3^{\prime}$ vicinity of the cloned sequence (Fig. 3h). One overlapping and two other incomplete binding sites are also present in the K10C3.4 3' UTR. Three of the four sites are conserved among both of the nematode orthologs.

To examine whether the K10C3.4 3' UTR mediates downregulation of the gene, we compared the expression from the reporter construct K10C3.4prom::lacZ::K10C3.4UTR with that of another reporter construct, K10C3.4prom::lacZ::unc$54 U T R$ (see Fig. 3a). Each of the constructs was mixed with a marker construct K10C3.4prom::GFP::unc-54UTR to generate transgenic lines, and worms of the lines were stained with $\mathrm{X}$-gal. Because GFP fluorescence in a cell reveals transmission of both the reporter and marker constructs into the cell, worms were scored for X-gal staining in fluorescent cells, especially in seam cells, at the $\mathrm{L}_{4}$ and young-adult stages. While lac $Z$ was expressed in most worms of K10C3.4prom::lacZ::unc-54UTR lines (Fig. 4a,b), lacZ expression was repressed in most worms of K10C3.4prom:: lacZ::K10C3.4UTR lines, although several head and tail unidentified cells expressed lac $Z$ in many of the worms (Fig. 4c-e). To determine whether the repression was dependent on let-7 miRNA, worms of the same K10C3.4prom:: lacZ::K10C3.4UTR lines were scored for X-gal staining in a temperature-sensitive let-7(n2853) background. The repression was partially relieved at the restrictive temperature (Fig. 4e). To know whether the let-7 binding sites are required for the repression, base substitutions were introduced to the sites (see Fig. 3h). Although lacZ expression in worms of K10C3.4prom::lacZ::K10C3.4UTR lines containing base substitutions in sites 2 and 3 was repressed compared with the expression in worms of the lines containing no substitutions, the repression was partially relieved in worms of $\mathrm{K} 10 \mathrm{C}$ 3.4prom::lacZ::K10C3.4UTR lines containing substitutions in all four of the sites (Fig. 4e). These results indicate that expression of K10C3.4 is down-regulated by let-7 miRNA via the let-7 binding sites in the $3^{\prime}$ UTR.

To test that the down-regulation mediated by the $3^{\prime}$ UTR also suppressed the bursting phenotype provoked by the expression of K10C3.4prom::K10C3.4::unc-54UTR, worms of K10C3.4prom::K10C3.4::K10C3.4UTR lines were scored for bursting (see Fig. 3a). Bursting through the vulva occurs 


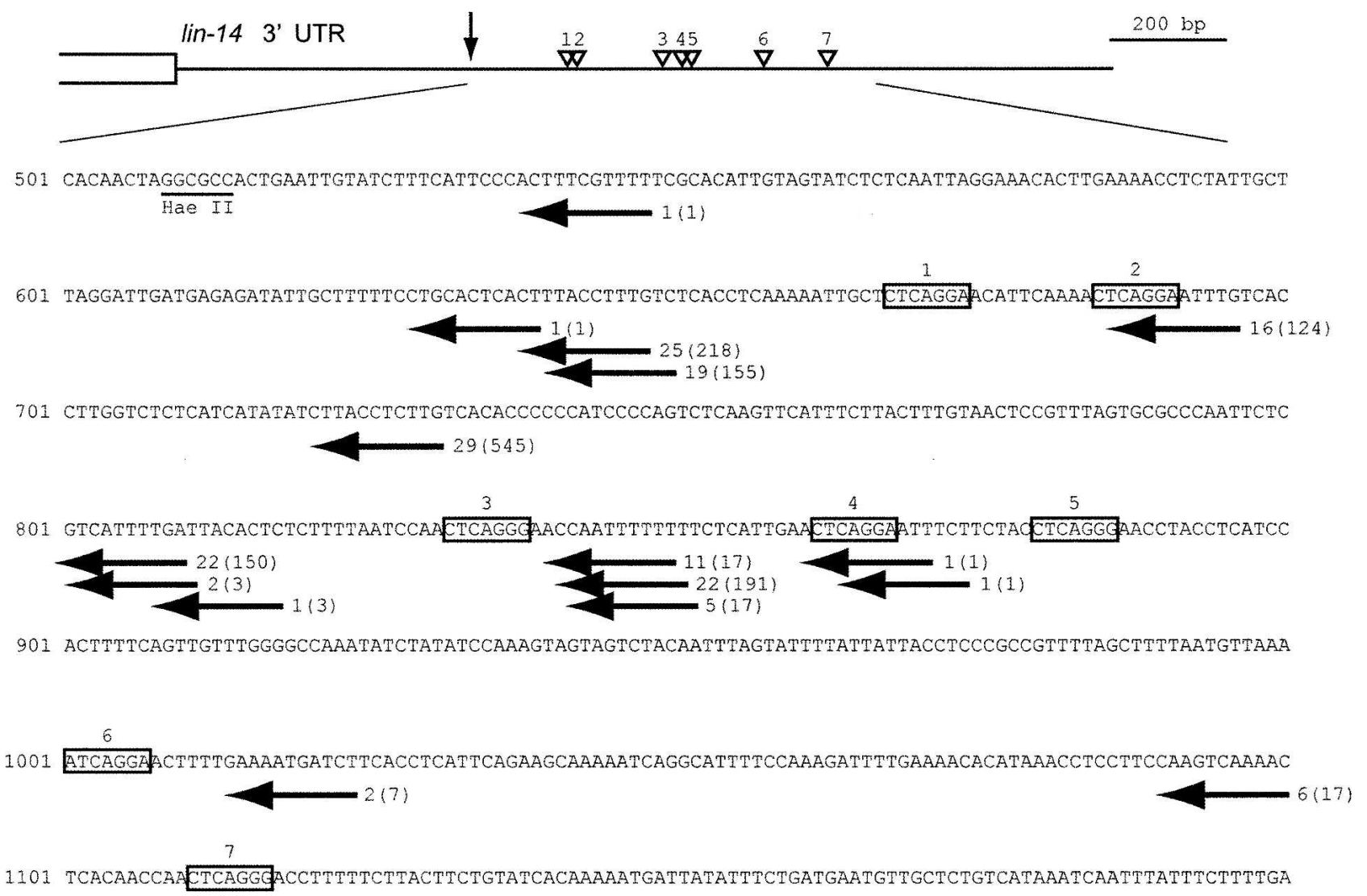

FIGURE 2. lin-14 3' UTR clones isolated to identify lin-4 targets. Schematic of the lin-14 3' UTR is depicted at the top where a HaeII recognition site is indicated with an arrow and lin- 4 binding sites are shown by open triangles $(\nabla)$. Partial sequence of the lin-14 $3^{\prime}$ UTR is written where the lin-4 binding sites are surrounded by rectangles. The $3^{\prime}$ termini of cloned sequences are indicated by horizontal arrows. The numeral shows the number of cDNA libraries from which at least one clone corresponding to the arrow was isolated and the total number of clones is in parentheses. Note that no other lin-14 3' UTR clones were isolated.

at two distinct adult stages, the young-adult stage (Fig. 4f) and the gravid-adult stage (Fig. 4g). Compared with the K10C3.4prom::K10C3.4::unc-54UTR lines, the frequency of bursting was significantly decreased in the K10C3.4 prom::K10C3.4::K10C3.4UTR lines at both of these adult stages (Fig. 4j). The vulval bursting phenotype in let7(mn112) was also suppressed by K10C3.4(RNAi), which depleted K10C3.4 products (Fig. 4h,i); the reproducibility of the suppression was assessed with $g f p(R N A i)$ as a negative control (Fig. 4k). It is unlikely that the RNAi suppression was due to defects in the development of the vulva, because wild-type worms subjected to K10C3.4 (RNAi) grew into adults with the ability to lay eggs (data not shown). Although let-7(mn112); K10C3.4(RNAi) worms survived the young-adult stage when all let-7(mn112) worms died (Fig. 4h), almost all of the worms were fated to suffer vulval bursting after the generation of many fertilized eggs without egg laying (Fig. 4i), suggesting that the downregulation of K10C3.4 is necessary for an early event in the development of a functional vulva. In conclusion, K10C3.4 is one of the let-7 targets responsible for the vulval bursting phenotype.

\section{DISCUSSION}

We have described here a method to efficiently synthesize cDNAs from target mRNAs using endogenous miRNAs as reverse-transcription primers and to identify target genes of a miRNA of interest by the cloning of cDNAs containing the sequence of the miRNA. The method was applied to lin-4, resulting in the isolation of many cDNA clones of the target gene lin-14. Application of the method to let-7 and subsequent experimental validation of genes corresponding to isolated clones demonstrated that K10C3.4 is a new target gene of let-7.

In many of the cloned lin-14 sequences, the $3^{\prime}$ terminus of each clone was located in nearly the full-length of the lin-4 miRNA from any one of the lin-4 binding sites, indicating that miRNAs binding to the binding site in vivo were utilized as primers for reverse transcription. In the other cloned sequences, the $3^{\prime}$ terminus of each clone was located apart from the binding sites, suggesting that some lin-4 miRNAs bind to lin-14 mRNAs with large internal bulges tolerated. The number of positions aligned with the $3^{\prime}$ termini is 16 , which is greater than the number of $\operatorname{lin}-4$ 
TABLE 1. RNAi suppression of the vulval bursting phenotype in let-7 mutants

\begin{tabular}{|c|c|c|c|c|}
\hline $\begin{array}{l}\text { Sequence } \\
\text { name }\end{array}$ & $\begin{array}{l}\text { Gene } \\
\text { name }\end{array}$ & $\begin{array}{l}\text { cDNA } \\
\text { template }^{a}\end{array}$ & $\begin{array}{l}\text { Injection } \\
\text { RNAi }^{\mathrm{b}}\end{array}$ & $\begin{array}{l}\text { Soaking } \\
\text { RNAi }^{5}\end{array}$ \\
\hline C05D2.1 & daf-4 & $y k 133 f 10$ & 0 & 0 \\
\hline C07A12.4 & pdi-2 & yk168d5 & Emb & 3 \\
\hline C07H6.5 & cgh-1 & yk641g3 & Few $F_{1}$ & 1 \\
\hline C08B11.3 & & yk323c8 & $\mathrm{Emb}$ & 1 \\
\hline C05D11.4 & let-756 & yk1597e10 & 0 & NT \\
\hline C52A11.4 & $m p z-1$ & yk31g8 & 0 & 0 \\
\hline F14B4.2 & & yk649e12 & 0 & 0 \\
\hline $\mathrm{F} 17 \mathrm{C} 11.1$ & & yk404e2 & 0 & 0 \\
\hline F23H12.4 & $s q t-3$ & yk312g1 & Lva & 8 \\
\hline $\mathrm{F} 25 \mathrm{H} 2.11$ & tct-1 & yk1668c11 & 0 & 0 \\
\hline $\mathrm{F} 25 \mathrm{H} 2.8$ & $u b c-25$ & yk487c5 & 0 & 2 \\
\hline F26E4.11 & hrdl-1 & yk360c1 & 1 & 0 \\
\hline F29D11.2 & & yk559f12 & Few $F_{1}$ & 0 \\
\hline F46B6.7 & $z t f-7$ & yk600e4 & 0 & 1 \\
\hline F46E10.10 & & yk117h2 & 1 & 0 \\
\hline F46H5.3 & & yk1479f07 & 0 & NT \\
\hline $\mathrm{F} 46 \mathrm{H} 5.7$ & & yk674d4 & 0 & 0 \\
\hline F53A3.3 & rps-22 & yk1587h09 & Few $F_{1}$ & Lva \\
\hline F54E4.1 & $r b c-1$ & yk30a4 & 0 & 0 \\
\hline F54E7.7 & ren-1 & yk1129e08 & 0 & 0 \\
\hline F54F2.2 & $z f p-1$ & yk473e12 & 0 & 0 \\
\hline F56D12.5 & vig-1 & yk301g7 & 0 & 1 \\
\hline F57B9.10 & $r p n-6$ & yk311c12 & Emb & Lva \\
\hline F59B10.1 & pqn-47 & yk561g4 & 8 & Lva \\
\hline K07A1.7 & & & 0 & 0 \\
\hline K08F8.1 & & yk640f9 & 0 & 0 \\
\hline K10C3.4 & & yk1100d10 & 7 & 1 \\
\hline R09G11.2 & $n h r-1$ & yk65f10 & 0 & 0 \\
\hline R09H10.4 & ptr-14 & $y k 270 g 10$ & 0 & 1 \\
\hline T04C10.4 & atf-5 & yk20a12 & 0 & NT \\
\hline T06D8.7 & & yk615b1 & 0 & NT \\
\hline T09A12.4 & $n h r-66$ & yk374f3 & 0 & 0 \\
\hline T14B1.1 & & yk232d5 & 1 & 0 \\
\hline W02A2.3 & pqn-74 & yk506f12 & 0 & NT \\
\hline W08E12.7 & & $y k 82 d 7$ & 0 & 1 \\
\hline Y38C1AA.4 & $t c l-2$ & yk643h1 & 0 & 0 \\
\hline Y54E5B.4 & $u b c-16$ & yk137b4 & 0 & 0 \\
\hline Y75B12B.5 & cyn-3 & yk428f4 & 0 & NT \\
\hline ZC404.9 & gck-2 & yk490f5 & 0 & 0 \\
\hline ZK470.2 & & yk426g2 & 0 & 0 \\
\hline
\end{tabular}

${ }^{\mathrm{a}}$ The names of cDNA clones (provided by the extensive $C$. elegans cDNA project, Y. Kohara, http://nematode.lab.nig.ac.jp/) used as templates to prepare dsRNA samples. The dsRNA sample of the K07A1.7 gene was produced using a cDNA clone isolated to identify let-7 targets.

${ }^{b}$ The number of worms with multiple fertilized eggs among about 50 worms subjected to injection RNAi and soaking RNAi, respectively. (Few $F_{1}$ ) Worms subjected to injection RNAi generated a few worms of $\mathrm{F}_{1}$ progeny, (Emb) Embryonic lethal; (Lva) Larval arrest; (NT) Not tested. As a criterion for RNAi suppression, the generation of multiple fertilized eggs in two or more worms subjected to RNAi was adopted.

binding sites, suggesting that the $3^{\prime}$ ends of lin-4 miRNAs that bind to a binding site do not necessarily bind to one strictly determined position, but instead can bind to several positions in the mRNA. Because sequences $3^{\prime}$ adjacent to the cloned sequences are complementary to at least one nucleotide from the $3^{\prime}$ end of the lin-4 miRNA, additional positions binding to the lin-4 miRNA with the $3^{\prime}$-end nucleotide unpaired may not have been detected by this means. The number of cDNA libraries from which at least one clone corresponding to each position was isolated substantially differed among the positions. The utilization of each position can be influenced by the sequence of the nearest lin- 4 binding site, the distance from the site, and the complementarity in the $3^{\prime}$-flanking sequence to the $3^{\prime}$ end of the lin-4 miRNA, although none of these factors were strongly correlated to the difference in utilization.

Of the genes corresponding to cDNA clones containing the let-7 miRNA sequence, the K10C3.4 gene was extensively studied in an attempt to identify a new target gene of let-7. The expression from the K10C3.4 promoter overlapped with that from the let-7 promoter in several tissues, including the vulva and seam cells. The expression of reporter genes with the K10C3.4 3' UTR was repressed in a manner dependent on the let-7 miRNA and let-7 binding sites in the K10C3.4 3' UTR. Overproduction and depletion of K10C3.4 products correlated with the occurrence of bursting through the vulva, which is one of the phenotypes in let-7 mutants. These results indicate that K10C3.4 is one of the let-7 targets responsible for the vulval bursting phenotype, although the function of K10C3.4 itself is still unknown. In the reporter studies, the mutation in let-7 and the base substitutions of let-7 binding sites in the $3^{\prime}$ UTR only partially relieved the repression mediated by the $3^{\prime}$ UTR, suggesting the presence of other regulators that also affect the K10C3.4 3' UTR. Indeed, after we applied the method to 15 other C. elegans miRNAs, cDNA clones of the K10C3.4 3' UTR were isolated for two of the miRNAs, which were shown to be expressed in the vulva and seam cells (Y. Andachi, unpubl.). This finding suggests that the expression of the K10C3.4 gene is under regulation by multiple kinds of miRNAs.

In addition to K10C3.4, 72 genes were detected by the isolation of cDNA clones. To explore the possibility that these genes are also let-7 targets, we deduced base pairing between the $3^{\prime}$-flanking sequence of each cloned sequence and the let-7 miRNA, and examined whether the sequence in base pairing is conserved in orthologous genes of

TABLE 2. Bursting through the vulva provoked by expression of the gene without regulation mediated by the 3' UTR

\begin{tabular}{lc}
\hline Gene & Percent of worms ${ }^{\text {a }}$ \\
\hline pdi-2 & $0.0 \pm 0.0$ \\
sqt-3 & $0.0 \pm 0.0$ \\
ubc-25 & $0.7 \pm 1.0$ \\
pqn-47 & $0.7 \pm 1.0$ \\
K10C3.4 & $16.9 \pm 3.3$ \\
\hline
\end{tabular}

${ }^{\mathrm{a}}$ Frequency of vulval bursting in transgenic worms among two transgenic lines with 100 or more worms per line (mean \pm SD). 


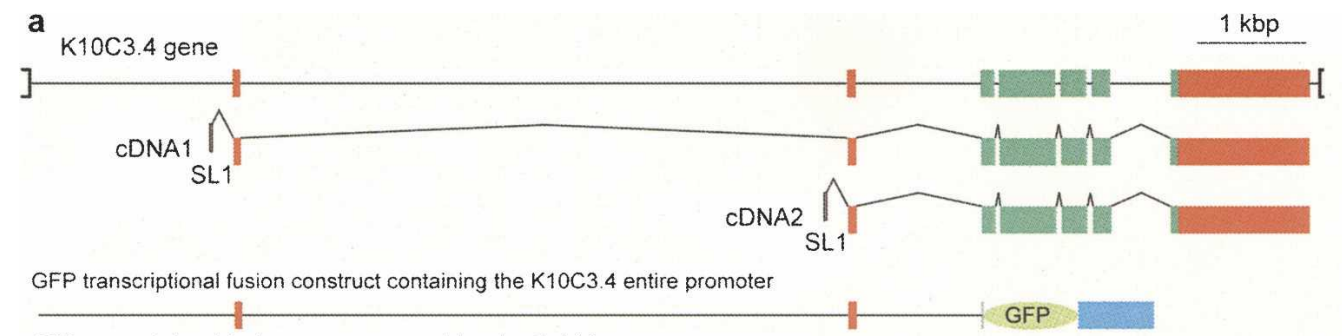

GFP transcriptional fusion construct containing the K10C3.4 upstream promoter I GFP

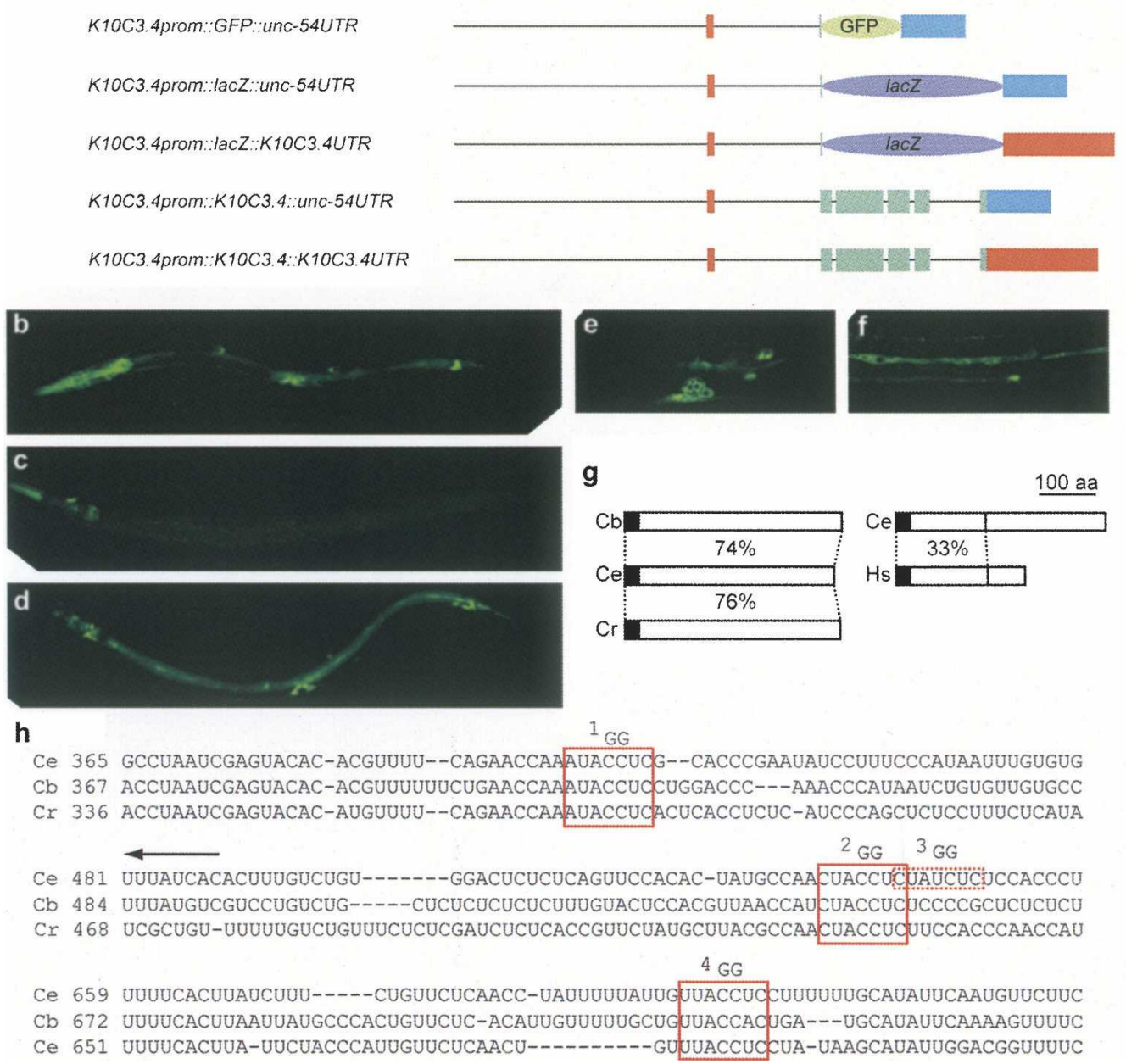

FIGURE 3. Gene expression and orthologs of K10C3.4. (a) Coding regions and UTRs are drawn in green and red, respectively. The structures of plasmid constructs used in this study are also shown. $(b-d)$ The expression of a GFP reporter containing the entire promoter $(b)$, upstream promoter $(c)$, and downstream promoter $(d) .(e, f)$ The localization of a GFP fusion protein in vulval cells $(e)$ and in seam cells $(f)$ of the same animal. All worms are at the $\mathrm{L}_{4}$ stage and the anterior is to the left. $(g)$ Amino acid identities between orthologs. (Ce) C. elegans; (Cb) C. briggsae; (Cr) C. remanei; (Hs) Homo sapiens Transmembrane protein 98. Transmembrane domains are shown in black. (h) Alignment of 3' UTR sequences. Numbers represent the leftmost nucleotides in base pairs downstream of the start of the $3^{\prime}$ UTRs. Conserved sequences complementary to the let-7 seed are surrounded by large rectangles. A nonconserved complementary sequence is denoted by a small hashed rectangle. Nucleotide substitutions are shown on the sequences along with the site number. An arrow indicates the $3^{\prime}$ terminus of the cloned sequence. 

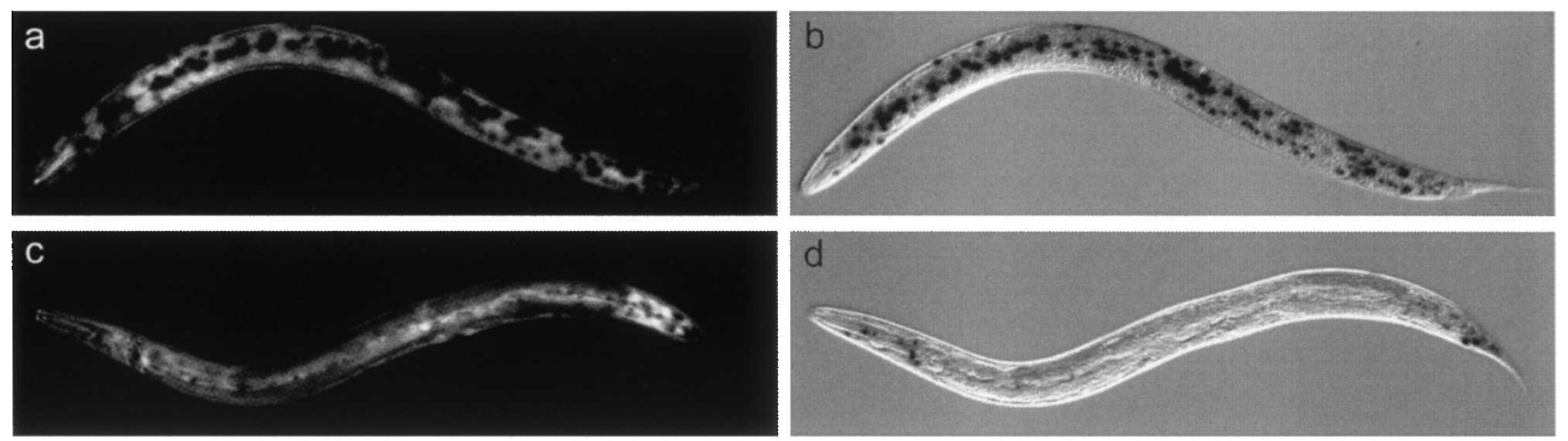

e
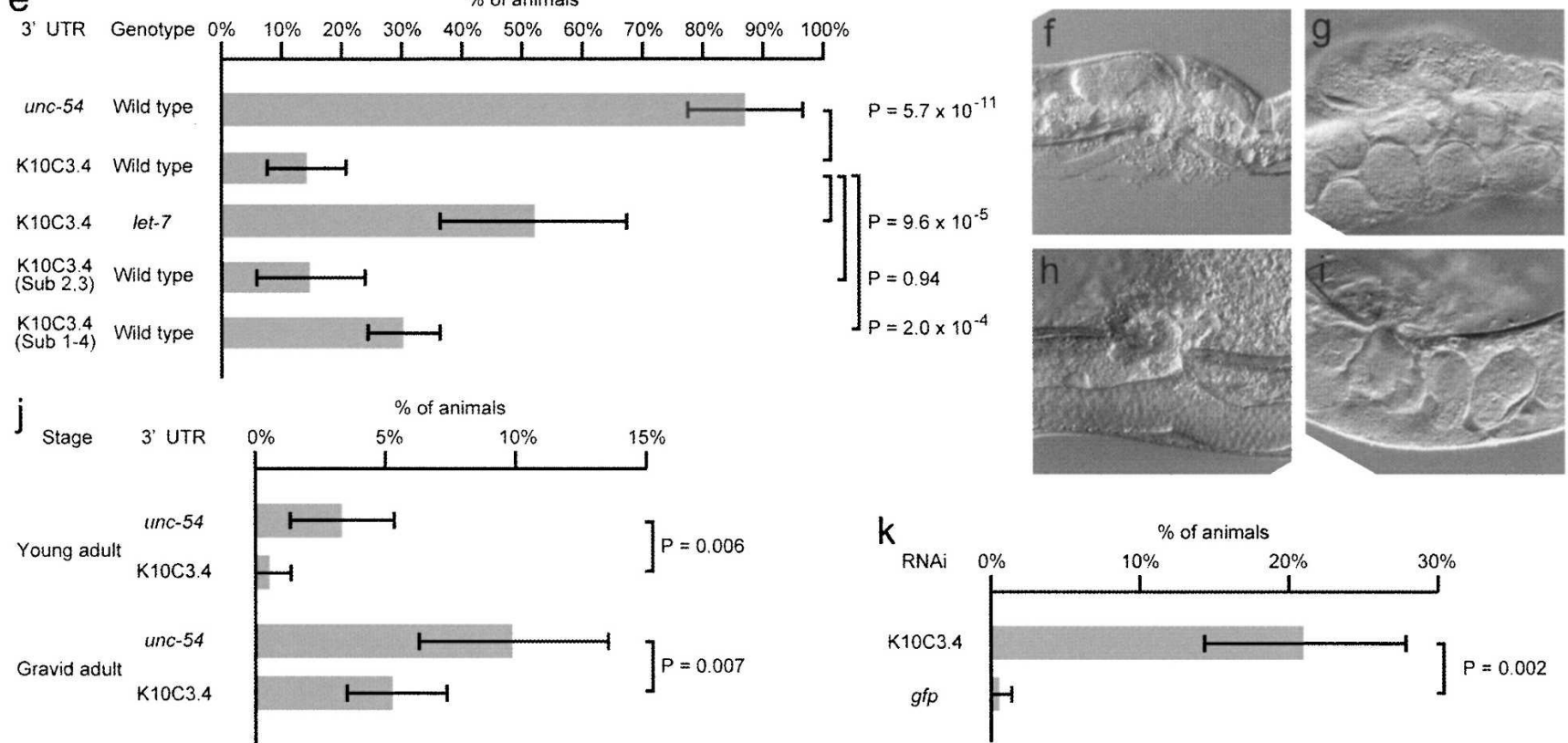

$\mathrm{k}$

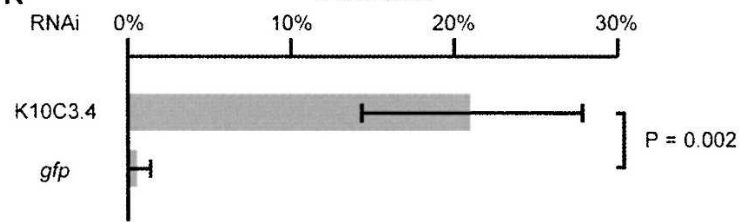

FIGURE 4. Down-regulation of K10C3.4 and involvement of K10C3.4 in the let-7 vulval bursting phenotype. $(a-d)$ Expression of a lac $Z$ construct containing unc-54 3' UTR $(a, b)$ and K10C3.4 3' UTR $(c, d)$. Photos show GFP fluorescence $(a, c)$ and bright field $(b, d)$ images. Both worms are at the $\mathrm{L}_{4}$ stage and the anterior is to the left. Note that lacZ expression is repressed except in several head and tail cells in $(d)$. $(e)$ Frequency of lac $Z$ expression among eight transgenic lines with 20 or more worms per line. $(f-i)$ Bursting through the vulva in a K10C3.4 transgenic line containing the unc-54 $3^{\prime}$ UTR at the young-adult stage $(f)$ and at the gravid-adult stage $(g)$, and in let-7(mn112) unc-3(e151) (h) and in let-7(mn112) unc-3(e151); K10C3.4(RNAi) (i). Note that many fertilized eggs were generated in $i$. (j) Frequency of vulval bursting in K10C3.4 transgenic worms among eight transgenic lines with 100 or more worms per line. (k) Frequency of survival at the young-adult stage in let-7(mn112) unc-3(e151) subjected to RNAi in five separate tests with 100 or more worms per test. Bars are mean \pm SD, and a two-tailed, Student's $t$-test was used to determine significance $(e, j, k)$.

C. briggsae and C. remanei (Supplemental Fig. 1). Of 40 genes in which $3^{\prime}$ termini of the cloned sequences were located in the $3^{\prime}$ UTRs or in the coding regions close to the 3' UTRs, perfect seed pairings were found for five genes, including K10C3.4. Interestingly, the perfect seed pairings were fully conserved in orthologs of the genes and all of the sites were also predicted to be let-7 binding sites by at least one computational algorithm (Lewis et al. 2003; Lall et al. 2006; Griffiths-Jones et al. 2008). Sequences partially complementary to the let-7 seed can also be functional let-7 binding sites, because some in vivo experiments have shown that miRNA seed pairing allows $G$ : $U$ wobble pairs and can tolerate single-base mismatches and single-base bulges for the repression of targets, especially when the $3^{\prime}$ half of the miRNA forms a continuum of base pairs with the targets (Brennecke et al. 2005; Didiano and Hobert 2006, 2008). Of the remaining 35 genes, 32 fulfilled the criteria for seed pairing and many of them also formed a continuum of base pairs with the $3^{\prime}$ half of the let-7 miRNA. More importantly, the partial seed pairings were highly conserved, even including unpaired nucleotides for 20 genes, suggesting that the partial let-7 binding sites in the 20 genes are functional for regulation in the nematodes. Of 33 genes in which the $3^{\prime}$ termini of the cloned sequences were located in the coding regions, perfect seed pairings were found for four genes and the other 18 genes fulfilled 
the criteria for seed pairing. However, for all four of the genes with perfect seed pairings and 13 of the other 18 genes, the sequences for seed pairings were not conserved in orthologous genes, but mainly by many synonymous substitutions. Therefore, it is plausible that the sequences are functional for the regulation of these genes. One hypothesis to explain these results is that the let-7 miRNA in the RISC binds to mRNAs by forming base pairs with sequences complementary to the seed without distinction between the 3' UTR and the coding region, and the RISC binding to the coding region is disabled for effects on the mRNAs and removed from the mRNAs. Our study might have isolated cDNA clones derived from transient let-7 miRNAs binding to the coding regions.

In the clones isolated to identify let-7 target genes, no cDNA clones corresponding to known let-7 targets were included. It is likely that the analysis of 96 clones for one cDNA library was not enough to isolate clones of these genes because of the low amounts of cDNAs derived from these genes. Aiming at the detection of the cDNAs, the samples of PCR products for preparation of CDNA libraries were subjected to amplification with a let-7 PCR primer and a gene-specific primer corresponding to sequences in the $5^{\prime}$ vicinity of the let-7 binding sites in the $5^{\prime}$-to- $3^{\prime}$ direction. One tested gene was daf-12, with which the $3^{\prime}-$ end nucleotides of the let-7 miRNA forms base pairs near one binding site (Grosshans et al. 2005), and the other was lin-41, with which the $3^{\prime}$ half of the let-7 miRNA forms a continuum of base pairs near two binding sites, but a few $3^{\prime}$-end nucleotides are kept unpaired (Slack et al. 2000) (Supplemental Fig. 2). Amplification by PCR with a daf-12 primer yielded fragments, and the analysis of cloned fragments revealed that the $3^{\prime}$ terminus of the cloned daf-12 sequence was located exactly next to the nucleotide with which the $3^{\prime}$-end nucleotide of the let-7 miRNA forms a base pair (Supplemental Fig. 2), indicating that our method can produce cDNAs from the known let-7 target and that the analysis of clones other than the 96 clones for one library possibly allows identification of other let-7 targets. On the other hand, no fragments derived from the lin-41 mRNA and containing the let-7 sequence were obtained by PCR with a lin-41 primer (data not shown), suggesting that let-7 miRNAs binding to target mRNAs with the 3 '-end nucleotide unpaired cannot be used as a reverse-transcription primer to synthesize cDNAs from the mRNAs. Nevertheless, as discussed above with respect to the isolated lin-14 clones, the $3^{\prime}$ end of miRNAs binding to a target mRNA by the seed can form base pairs with sequences in more than one position of the mRNA. If the 3 -end nucleotide of the miRNA forms base pairs in some of the positions, the miRNA can serve in reverse transcription of the mRNA.

In contrast to the microarray approach, our biochemical method for identifying target genes of individual miRNAs has the advantage that the cell extract from one sample from any kind of strain is sufficient. Therefore, our method can be easily applied to a variety of animal species. Our method can also provide information on how the miRNA forms base pairs with cloned mRNAs, which helps to assess whether the miRNA plays a functional role on the mRNAs. Small interference RNA (siRNA), another small RNA similar to miRNA, is utilized as an exogenously supplied material to repress the expression of intended genes. A wellknown problem with such experiments is that supplied siRNA also down-regulates incidental, nontargeted genes, or off-target genes (Jackson et al. 2003; Semizarov et al. 2003; Scacheri et al. 2004). It has been reported that downregulation of off-target genes by siRNA is executed in the same manner as miRNA (Birmingham et al. 2006; Jackson et al. 2006). Therefore, our method may also be used for the detection of off-target genes in siRNA experiments.

\section{MATERIALS AND METHODS}

\section{Strains}

Strains and mutant alleles used in this study: wild-type Bristol N2, $m n D p 1(X ; V) /+V$; let-7(mn112) unc-3(e151) X (the strain SP231), and let-7(n2853) $X$. Standard C. elegans cultivation techniques were used for all worm handling (Sulston and Hodgkin 1988). Worms were grown at $20^{\circ} \mathrm{C}$, except for worms containing the let$7(n 2853)$ allele, which were grown at the permissive temperature, $15^{\circ} \mathrm{C}$, and at the restrictive temperature, $20^{\circ} \mathrm{C}$.

\section{Isolation of cDNA clones to identify targets of a miRNA of interest}

Worm N2 eggs were collected by the alkaline hypochlorite procedure. The eggs were cultivated in $\mathrm{S}$ medium containing $E$. coli strain OP50 for $24,36,48$, and $60 \mathrm{~h}$ to harvest worms at the $\mathrm{L}_{2}, \mathrm{~L}_{3}, \mathrm{~L}_{4}$, and young-adult stages, respectively. The worms were cleaned by the sucrose flotation procedure and homogenized in 10 vol of Cell Fractionation Buffer of PARIS (Ambion) with a homogenizer. The extract was centrifuged at $20,000 \mathrm{~g}$ for $5 \mathrm{~min}$ to precipitate cell debris and nuclei. The supernatant was mixed with $0.1 \mathrm{vol}$ of $10 \%$ sodium dodecyl sulfate (SDS) and incubated on ice for $1 \mathrm{~min}$. The treated supernatant was incubated in $200 \mathrm{vol}$ of pre-chilled reverse-transcription reaction buffer (1X First-Strand Buffer, $10 \mathrm{mM}$ DTT, $50 \mathrm{ng} / \mu \mathrm{L}$ Actinomycin D, $0.5 \mathrm{mM} \mathrm{dNTP}, 1$ $\mathrm{U} / \mu \mathrm{L}$ RNasin Plus Ribonuclease Inhibitor [Promega], $5 \mathrm{U} / \mu \mathrm{L}$ Superscript III [Invitrogen]) to synthesize a first-strand cDNA using the miRNA as a primer. Actinomycin D was included in the buffer to prevent the synthesis of second-strand cDNA. The incubation temperature was first gradually raised from $4^{\circ} \mathrm{C}$ to $37^{\circ} \mathrm{C}$ in $10 \mathrm{~min}$, and then kept at $37^{\circ} \mathrm{C}$ for $60 \mathrm{~min}$. The reaction buffer was mixed with $0.02 \mathrm{vol}$ of $10 \%$ SDS and extracted with phenol/chloroform/isoamyl alcohol (25:24:1, pH 9.5). Polynucleotides in the buffer were collected by ethanol precipitation and incubated in reaction buffer (1X reverse transcription buffer, 1 $\mathrm{mM} \mathrm{MnCl} 2,0.2 \mathrm{mM}$ dNTP, $1 \mathrm{U} / \mu \mathrm{L}$ RNasin Plus Ribonuclease Inhibitor, $0.2 \mathrm{U} / \mu \mathrm{L}$ Tth DNA Polymerase [Promega]) at $25^{\circ} \mathrm{C}$ for $10 \mathrm{~min}$, followed by $70^{\circ} \mathrm{C}$ for $30 \mathrm{~min}$ to synthesize DNA complementary to both the first-strand cDNA and the miRNA. The double-stranded cDNA was purified with a PCR purification 
kit (Qiagen) and digested by a restriction endonuclease as follows. In experiments for lin-4 targets, the restriction endonuclease was HaeII (Promega). In experiments for let-7 targets, either NlaIII (NEB) or TaiI (Fermentas) was used. Because these endonucleases recognize four nucleotides consisting of $A, T, G$, and $C$, it was expected that most, if not all, let-7 targets contain at lease one recognition site of the endonucleases. The digested cDNA fragments were ligated to an adapter oligonucleotide and amplified by PCR with an adapter PCR primer from the adapter sequence and a biotin-tagged miRNA PCR primer corresponding to a partial sequence of the miRNA. The annealing temperatures for lin-4 and let-7 miRNA PCR primers were $55^{\circ} \mathrm{C}$ and $48^{\circ} \mathrm{C}$, respectively, which were experimentally determined as the highest temperatures able to amplify the miRNA genes from genomic DNA. Biotin-labeled PCR fragments were collected by binding to SoftLink Soft Release Avidin Resin (Promega). An aliquot of the collected PCR fragments was amplified by a second-round of nested PCR with a longer adapter PCR primer and a nested miRNA PCR primer containing the NotI recognition sequence. The PCR fragments were digested by NotI and the same restriction endonuclease as used for ligation of the adapter oligonucleotide, and cloned into a modified vector of pBluescript II KS+ (Stratagene), in which the recognition sequences of restriction endonucleases BbeI, SphI, and AatII were inserted in the PstI recognition site. The experiments for let-7 targets were performed in all six combinations of samples from three developmental stages and the two restriction endonucleases, except that the experiment combining the $\mathrm{L}_{4}$ sample and NlaIII was repeated twice, and 96 colonies were randomly picked from each cDNA library. The insert DNA of each clone was amplified by colony PCR with vector primers and the sequence of the PCR fragment was determined by the cycle-sequencing procedure on an ABI3730 sequencer (Applied Biosystems) with the vector primer near the NotI site. The adapter oligonucleotides are: 5'-TGCTA CTGGAGCGC-3' for HaeII; 5' -CCTACTGAGCATG-3' for NlaIII; and $5^{\prime}$-CCTACTGAGACGT-3' for TaiI. The biotin-tagged miRNA PCR primers are: 5' -biotin-TCCCTGAGACCTC-3' for lin-4; 5'-biotin-TGAGGTAGTAGGTT-3' for let-7. The longer adapter PCR primers are: 5'-ACTGATTGCTACTGGAGCGC-3' for HaeII; 5'-CAAGCAGTTGTCCTACTGAGCATG-3' for NlaIII; 5'-CAAGC AGTTGTCCTACTGAGACGT-3' for Tail. The nested miRNA PCR primers are: $5^{\prime}$-ATGCGGCCGCGAGACCTCAAGTG-3' for lin-4; 5'-ATGCGGCCGCTAGTAGGTTGTATA-3' for let-7. The vector primers are: 5'-ACACAGGAAACAGCTATGAC-3' and 5'-GCTG CAAGGCGATTAAGTTG-3'. The gene-specific PCR primers are: 5'-GCGTCGACTGCTTCTACATCTATCCTC-3' for daf-12; 5'-GC GTCGACGAACGAATTTTGTCGGAATATTTG-3' for lin-41. The oligonucleotide complementary to the lin-4 miRNA is $5^{\prime}$-UACAC UCACACUUGAGGUCUCAGGGAACAGG-3' ${ }^{\prime}$, in which all nucleotides are $2^{\prime}$-O-methylated.

\section{RNAi test for let-7 mutant suppression}

Double-stranded RNA (dsRNA) samples were produced from cDNA clones as previously described (Andachi 2004). For injection RNAi, the dsRNA was injected into fertile adult worms of the strain SP231 that were heterozygous for $m n D p 1(X ; V)$. About 50 worms of $\mathrm{F}_{1}$ progeny with the genotype let-7(mn112) unc-3(e151) that can be discriminated by the Unc-3 phenotype were transferred to another plate, and the worms were scored for the generation of many fertilized eggs. For soaking RNAi, $\mathrm{L}_{1}$ worms of the strain SP231 were soaked in buffer containing the dsRNA for $24 \mathrm{~h}$ as previously described (Maeda et al. 2001) and then allowed to feed on a plate for $24 \mathrm{~h}$. Unc-3 worms were transferred and scored by the same way as used in the injection RNAi.

\section{cDNAs, plasmid constructs, and transformants}

The cDNA clones and their sequences were obtained from the extensive C. elegans cDNA project (Y. Kohara, http://nematode. lab.nig.ac.jp/). Promoter regions, coding regions, and 3' UTRs of tested genes were amplified by PCR from C. elegans genomic DNA. The GFP and lacZ coding sequences were from the Fire vectors pPD95.79 and pPD95.07, respectively. Amplification fragments were joined to produce plasmid constructs that were proper arrangements of the three gene regions and all of the plasmid constructs were sequence verified. The PCR primer sequences are available in Supplemental Table 1. Each test plasmid was mixed with a marker plasmid that consisted of the promoter region from the same gene, the GFP coding region, and the unc-54 3' UTR. The plasmid mixture was injected into the gonads of N2 adult worms to generate transgenic lines. The concentrations of plasmids used for injection are $50 \mathrm{ng} / \mu \mathrm{L}$ for constructs containing coding regions of tested genes, $100 \mathrm{ng} / \mu \mathrm{L}$ for constructs containing the GFP coding region, and $10 \mathrm{ng} / \mu \mathrm{L}$ for constructs containing the lac $Z$ coding region. Worm photos were taken with a Nomarski microscope, model Axioplan2 (Zeiss) or a confocal laser scanning microscope, model LMS510 (Zeiss).

\section{Scoring for X-gal staining}

A single adult worm of transgenic lines containing lacZ expression plasmids was transferred to a plate and cultivated until many worms of $\mathrm{F}_{1}$ progeny were grown to $\mathrm{L}_{4}$ and young-adult stages. All worms on the plate were harvested and washed with the M9 buffer. The worms were fixed in buffer ( $80 \mathrm{mM}$ Hepes at $\mathrm{pH} 6.9$, $140 \mathrm{mM} \mathrm{NaCl}, 30 \mathrm{mM} \mathrm{KCl}, 40 \mathrm{mM} \mathrm{Na} \mathrm{HPO}_{4}, 15 \mathrm{mM} \mathrm{KH}_{2} \mathrm{PO}_{4}$, $1.6 \mathrm{mM} \mathrm{MgSO}_{4}, 0.8 \mathrm{mM}$ EGTA, $3.7 \%$ formaldehyde) at $28^{\circ} \mathrm{C}$ for $1 \mathrm{~h}$. After freeze drying and acetone permeabilization, the worms were stained in buffer $\left(17 \mathrm{mM} \mathrm{NaH}_{2} \mathrm{PO}_{4}, 83 \mathrm{mM} \mathrm{Na}_{2} \mathrm{HPO}_{4}, 2\right.$ $\mathrm{mM} \mathrm{MgCl}_{2}, 5 \mathrm{mM} \mathrm{K}_{4} \mathrm{Fe}(\mathrm{CN})_{6}, 5 \mathrm{mM} \mathrm{K}_{3} \mathrm{Fe}(\mathrm{CN})_{6}, 0.005 \%$ SDS, $0.024 \% \mathrm{X}$-gal) at $37^{\circ} \mathrm{C}$ for $2 \mathrm{~h}$. The same K10C3.4prom::lacZ::K10 C3.4UTR transgenes analyzed in the wild type were crossed into a let-7(n2853) genetic background. Both GFP fluorescence and Xgal staining of each worm were observed with the Nomarski microscopy illumination technique.

\section{SUPPLEMENTAL DATA}

Supplemental material can be found at http://www.rnajournal.org.

\section{ACKNOWLEDGMENTS}

I thank Y. Kohara for cDNA clones and A. Fire for pPD vectors. The let-7 mutant strains used in this work were provided by the Caenorhabditis Genetics Center, which is funded by the NIH National Center for Research Resources (NCRR). I thank members of the Kohara Laboratory for comments. This work was supported by a Grant-in-Aid for Exploratory Research from the Ministry of Education, Culture, Sports, Science and Technology of Japan to Y.A.

Received April 16, 2008; accepted July 23, 2008. 


\section{REFERENCES}

Abrahante, J.E., Daul, A.L., Li, M., Volk, M.L., Tennessen, J.M., Miller, E.A., and Rougvie, A.E. 2003. The Caenorhabditis elegans hunchback-like gene lin-57/hbl-1 controls developmental time and is regulated by microRNAs. Dev. Cell 4: 625-637.

Ambros, V., Lee, R.C., Lavanway, A., Williams, P.T., and Jewell, D. 2003. MicroRNAs and other tiny endogenous RNAs in C. elegans. Curr. Biol. 13: 807-818.

Andachi, Y. 2004. Caenorhabditis elegans T-box genes $t b x-9$ and $t b x-8$ are required for formation of hypodermis and body-wall muscle in embryogenesis. Genes Cells 9: 331-344.

Bagga, S., Bracht, J., Hunter, S., Massirer, K., Holtz, J., Eachus, R., and Pasquinelli, A.E. 2005. Regulation by let-7 and lin-4 miRNAs results in target mRNA degradation. Cell 122: 553-563.

Bartel, D.P. 2004. MicroRNAs: Genomics, biogenesis, mechanism, and function. Cell 116: 281-297.

Birmingham, A., Anderson, E.M., Reynolds, A., Ilsley-Tyree, D., Leake, D., Fedorov, Y., Baskerville, S., Maksimova, E., Robinson, K., Karpilow, J., et al. 2006. 3' UTR seed matches, but not overall identity, are associated with RNAi off-targets. Nat. Methods 3: 199-204.

Brennecke, J., Stark, A., Russell, R.B., and Cohen, S.M. 2005. Principles of microRNA-target recognition. PLoS Biol. 3: 404-418.

Didiano, D. and Hobert, O. 2006. Perfect seed pairing is not a generally reliable predictor for miRNA-target interactions. Nat. Struct. Mol. Biol. 13: 849-851.

Didiano, D. and Hobert, O. 2008. Molecular architecture of a miRNA-regulated 3' UTR. RNA 14: 1297-1317.

Easow, G., Teleman, A.A., and Cohen, S.M. 2007. Isolation of microRNA targets by miRNP immunopurification. RNA 13: 1198-1204.

Esquela-Kerscher, A., Johnson, S.M., Bai, L., Saito, K., Partridge, J., Reinert, K.L., and Slack, F.J. 2005. Post-embryonic expression of $C$. elegans microRNAs belonging to the lin-4 and let-7 families in the hypodermis and the reproductive system. Dev. Dyn. 234: 868-877.

Feinbaum, R. and Ambros, V. 1999. The timing of lin-4 RNA accumulation controls the timing of postembryonic developmental events in Caenorhabditis elegans. Dev. Biol. 210: 87-95.

Flicek, P., Aken, B.L., Beal, K., Ballester, B., Caccamo, M., Chen, Y., Clarke, L., Coates, G., Cunningham, F., Cutts, T., et al. 2008. Ensembl 2008. Nucleic Acids Res. 36: D707-D714.

Friedlander, M.R., Chen, W., Adamidi, C., Maaskola, J., Einspanier, R., Knespel, S., and Rajewsky, N. 2008. Discovering microRNAs from deep sequencing data using miRDeep. Nat. Biotechnol. 26: 407-415.

Giraldez, A.J., Mishima, Y., Rihel, J., Grocock, R.J., Van Dongen, S., Inoue, K., Enright, A.J., and Schier, A.F. 2006. Zebrafish MiR-430 promotes deadenylation and clearance of maternal mRNAs. Science 312: 75-79.

Grad, Y., Aach, J., Hayes, G.D., Reinhart, B.J., Church, G.M., Ruvkun, G., and Kim, J. 2003. Computational and experimental identification of C. elegans microRNAs. Mol. Cell 11: 1253-1263.

Griffiths-Jones, S., Saini, H.K., van Dongen, S., and Enright, A.J. 2008. miRBase: Tools for microRNA genomics. Nucleic Acids Res. 36: D154-D158.

Grosshans, H., Johnson, T., Reinert, K.L., Gerstein, M., and Slack, F.J. 2005. The temporal patterning microRNA let-7 regulates several transcription factors at the larval to adult transition in C. elegans. Dev. Cell 8: 321-330.

Gu, S.G., Pak, J., Barberan-Soler, S., Ali, M., Fire, A., and Zahler, A.M. 2007. Distinct ribonucleoprotein reservoirs for microRNA and siRNA populations in C. elegans. RNA 13: 1492-1504.

Ha, I., Wightman, B., and Ruvkun, G. 1996. A bulged lin-4/lin-14 RNA duplex is sufficient for Caenorhabditis elegans lin-14 temporal gradient formation. Genes \& Dev. 10: 3041-3050.

Hayes, G.D., Frand, A.R., and Ruvkun, G. 2006. The mir-84 and let-7 paralogous microRNA genes of Caenorhabditis elegans direct the cessation of molting via the conserved nuclear hormone receptors NHR-23 and NHR-25. Development 133: 4631-4641.
Jackson, A.L., Bartz, S.R., Schelter, J., Kobayashi, S.V., Burchard, J., Mao, M., Li, B., Cavet, G., and Linsley, P.S. 2003. Expression profiling reveals off-target gene regulation by RNAi. Nat. Biotechnol. 21: 635-637.

Jackson, A.L., Burchard, J., Schelter, J., Chau, B.N., Cleary, M., Lim, L., and Linsley, P.S. 2006. Widespread siRNA "off-target" transcript silencing mediated by seed region sequence complementarity. RNA 12: 1179-1187.

Johnson, S.M., Lin, S.Y., and Slack, F.J. 2003. The time of appearance of the C. elegans let-7 microRNA is transcriptionally controlled utilizing a temporal regulatory element in its promoter. Dev. Biol. 259: $364-379$.

Johnson, S.M., Grosshans, H., Shingara, J., Byrom, M., Jarvis, R., Cheng, A., Labourier, E., Reinert, K.L., Brown, D., and Slack, F.J. 2005. RAS is regulated by the let-7 microRNA family. Cell 120: 635-647.

Karginov, F.V., Conaco, C., Xuan, Z., Schmidt, B.H., Parker, J.S., Mandel, G., and Hannon, G.J. 2007. A biochemical approach to identifying microRNA targets. Proc. Natl. Acad. Sci. 104: 1929119296.

Kloosterman, W.P. and Plasterk, R.H. 2006. The diverse functions of microRNAs in animal development and disease. Dev. Cell 11: $441-450$

Krek, A., Grun, D., Poy, M.N., Wolf, R., Rosenberg, L., Epstein, E.J., MacMenamin, P., da Piedade, I., Gunsalus, K.C., Stoffel, M., et al. 2005. Combinatorial microRNA target predictions. Nat. Genet. 37: 495-500.

Lagos-Quintana, M., Rauhut, R., Lendeckel, W., and Tuschl, T. 2001. Identification of novel genes coding for small expressed RNAs. Science 294: 853-858.

Lall, S., Grun, D., Krek, A., Chen, K., Wang, Y.L., Dewey, C.N., Sood, P., Colombo, T., Bray, N., Macmenamin, P., et al. 2006. A genome-wide map of conserved microRNA targets in C. elegans. Curr. Biol. 16: 460-471.

Lau, N.C., Lim, L.P., Weinstein, E.G., and Bartel, D.P. 2001. An abundant class of tiny RNAs with probable regulatory roles in Caenorhabditis elegans. Science 294: 858-862.

Lee, R.C. and Ambros, V. 2001. An extensive class of small RNAs in Caenorhabditis elegans. Science 294: 862-864.

Lee, R.C., Feinbaum, R.L., and Ambros, V. 1993. The C. elegans heterochronic gene lin-4 encodes small RNAs with antisense complementarity to lin-14. Cell 75: 843-854.

Lewis, B.P., Shih, I.H., Jones-Rhoades, M.W., Bartel, D.P., and Burge, C.B. 2003. Prediction of mammalian microRNA targets. Cell 115: 787-798.

Lim, L.P., Lau, N.C., Weinstein, E.G., Abdelhakim, A., Yekta, S., Rhoades, M.W., Burge, C.B., and Bartel, D.P. 2003. The microRNAs of Caenorhabditis elegans. Genes \& Dev. 17: 991-1008.

Lim, L.P., Lau, N.C., Garrett-Engele, P., Grimson, A., Schelter, J.M., Castle, J., Bartel, D.P., Linsley, P.S., and Johnson, J.M. 2005. Microarray analysis shows that some microRNAs downregulate large numbers of target mRNAs. Nature 433: 769-773.

Lin, S.Y., Johnson, S.M., Abraham, M., Vella, M.C., Pasquinelli, A., Gamberi, C., Gottlieb, E., and Slack, F.J. 2003. The C. elegans hunchback homolog, $h b l-1$, controls temporal patterning and is a probable microRNA target. Dev. Cell 4: 639-650.

Maeda, I., Kohara, Y., Yamamoto, M., and Sugimoto, A. 2001. Largescale analysis of gene function in Caenorhabditis elegans by highthroughput RNAi. Curr. Biol. 11: 171-176.

Miska, E.A., Alvarez-Saavedra, E., Abbott, A.L., Lau, N.C., Hellman, A.B., McGonagle, S.M., Bartel, D.P., Ambros, V.R., and Horvitz, H.R. 2007. Most Caenorhabditis elegans microRNAs are individually not essential for development or viability. PLoS Genet. 3: 2395-2403.

Ohler, U., Yekta, S., Lim, L.P., Bartel, D.P., and Burge, C.B. 2004. Patterns of flanking sequence conservation and a characteristic upstream motif for microRNA gene identification. RNA 10: 13091322. 
Rajewsky, N. 2006. microRNA target predictions in animals. Nat. Genet. 38: S8-13.

Reinhart, B.J., Slack, F.J., Basson, M., Pasquinelli, A.E., Bettinger, J.C., Rougvie, A.E., Horvitz, H.R., and Ruvkun, G. 2000. The 21nucleotide let-7 RNA regulates developmental timing in Caenorhabditis elegans. Nature 403: 901-906.

Rogers, A., Antoshechkin, I., Bieri, T., Blasiar, D., Bastiani, C., Canaran, P., Chan, J., Chen, W.J., Davis, P., Fernandes, J., et al. 2008. WormBase 2007. Nucleic Acids Res. 36: D612-D617.

Ruby, J.G., Jan, C., Player, C., Axtell, M.J., Lee, W., Nusbaum, C., Ge, H., and Bartel, D.P. 2006. Large-scale sequencing reveals 21URNAs and additional microRNAs and endogenous siRNAs in $C$. elegans. Cell 127: 1193-1207.

Ruby, J.G., Jan, C.H., and Bartel, D.P. 2007. Intronic microRNA precursors that bypass Drosha processing. Nature 448: 83-86.

Scacheri, P.C., Rozenblatt-Rosen, O., Caplen, N.J., Wolfsberg, T.G., Umayam, L., Lee, J.C., Hughes, C.M., Shanmugam, K.S., Bhattacharjee, A., Meyerson, M., et al. 2004. Short interfering RNAs can induce unexpected and divergent changes in the levels of untargeted proteins in mammalian cells. Proc. Natl. Acad. Sci. 101: 1892-1897.

Semizarov, D., Frost, L., Sarthy, A., Kroeger, P., Halbert, D.N., and Fesik, S.W. 2003. Specificity of short interfering RNA determined through gene expression signatures. Proc. Natl. Acad. Sci. 100: 6347-6352.
Slack, F.J., Basson, M., Liu, Z., Ambros, V., Horvitz, H.R., and Ruvkun, G. 2000. The lin-41 RBCC gene acts in the C. elegans heterochronic pathway between the let-7 regulatory RNA and the LIN-29 transcription factor. Mol. Cell 5: 659-669.

Stefani, G. and Slack, F.J. 2008. Small non-coding RNAs in animal development. Nat. Rev. Mol. Cell Biol. 9: 219-230.

Sulston, J. and Hodgkin, J. 1988. Methods. In The nematode Caenorhabditis elegans (ed. W.B. Wood), pp. 587-606. Cold Spring Harbor Laboratory Press, Cold Spring Harbor, NY.

Vatolin, S., Navaratne, K., and Weil, R.J. 2006. A novel method to detect functional microRNA targets. J. Mol. Biol. 358: 983-996.

Vella, M.C., Choi, E.Y., Lin, S.Y., Reinert, K., and Slack, F.J. 2004. The C. elegans microRNA let-7 binds to imperfect let-7 complementary sites from the lin-41 3' UTR. Genes \& Dev. 18: 132-137.

Wightman, B., Ha, I., and Ruvkun, G. 1993. Posttranscriptional regulation of the heterochronic gene lin-14 by lin-4 mediates temporal pattern formation in C. elegans. Cell 75: 855-862.

Zhang, L., Ding, L., Cheung, T.H., Dong, M.Q., Chen, J., Sewell, A.K., Liu, X., Yates 3rd., J.R., and Han, M. 2007. Systematic identification of C. elegans miRISC proteins, miRNAs, and mRNA targets by their interactions with GW182 proteins AIN-1 and AIN-2. Mol. Cell 28: 598-613. 

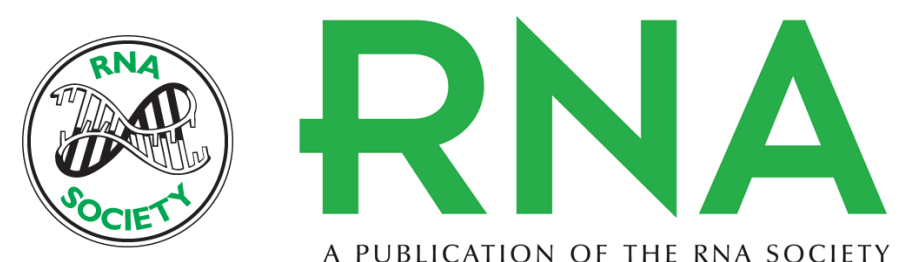

A PUBLICATION OF THE RNA SOCIETY

\section{A novel biochemical method to identify target genes of individual microRNAs: Identification of a new Caenorhabditis elegans let-7 target}

Yoshiki Andachi

RNA 2008 14: 2440-2451 originally published online September 29, 2008

Access the most recent version at doi:10.1261/rna.1139508

Supplemental http://rnajournal.cshlp.org/content/suppl/2008/09/29/rna.1139508.DC1

Material

References This article cites 53 articles, 16 of which can be accessed free at:

http://rnajournal.cshlp.org/content/14/11/2440.full.html\#ref-list-1

License

Email Alerting Receive free email alerts when new articles cite this article - sign up in the box at the Service top right corner of the article or click here. 